Original Article (short paper)

\title{
Relationship between carotid intima-media thickness, physical activity, sleep quality, metabolic/inflamatory profile, body fatness, smoking and alcohol consumption in young adults
}

\author{
Santiago Maillane-Vanegas \\ Bruna Camilo Turi-Lynch \\ Fabio Santos de Lira \\ Jamile Sanches Codogno \\ Rômulo Araújo Fernandes \\ Manoel Carlos Spiguel de Lima \\ Universidade Estadual Paulista (UNESP), Presidente Prudente, SP, Brazil \\ Aristides Machado-Rodrigues \\ Universidade de Coimbra, Coimbra, Portugal \\ Han C. G. Kemper \\ University Medical Center, Amsterdam, Netherlands
}

\begin{abstract}
Aim: The aim of this longitudinal study was to analyze the relationship between sleep disorder and intimamedia thickness. Method: Baseline measurements included carotid intima-media thickness, assessed by an ultrasound device; questionnaires about sleep and other behavioral variables; physical activity was measured by pedometer; body fatness was estimated by Dual-Energy X-ray Absorptiometry; fasting glucose, lipid profile and C-reactive protein were collected. Results: The occurrence rate of sleep-related disorders was $47 \%(95 \% \mathrm{CI}=37.2 \%-56.7 \%)$. Carotid intimamedia thickness was related to symptoms of insomnia ( $r=0.328$ [0.141 to 0.493$])$ and, after adjustments for potential confounders, the relationship between carotid intima-media thickness and insomnia remained statistically significant $(\beta=0.121[95 \% \mathrm{CI}=0.017 ; 0.225])$. Conclusions: In young adults, sleep disorder was significantly related to premature increase in carotid intima-media thickness.
\end{abstract}

Keywords: Aatherosclerosis, insulin resistance, lipid profile, diabetes mellitus.

\section{Introduction}

Sleep is a fundamental condition into the circadian rhythm, especially for the restoration of physiological systems ${ }^{1}$. Scientific literature generally states that humans spend about one-third of their time sleeping ${ }^{2}$. On the other hand, studies have shown that sleep time has decreased in different countries ${ }^{3-5}$ and insomnia is the most common sleep disorder in young and middle-aged adults ${ }^{6}$.

Recently, studies have shown that sleep disorders in adults have been associated with a large variety of diseases, such as obesity, arterial hypertension, dyslipidemia, and diabetes mellitus (DM) $)^{7-9}$, as well as increased cardiovascular morbidity/ mortality ${ }^{10,11}$. Nowadays, the harmful effects associated with sleep disorders happen among several age groups, besides the elderly ${ }^{12}$. Recent studies have consistently demonstrated a close relationship between sleep disorder and cardiovascular diseases in different age groups, including adolescents ${ }^{4,5,12}$.

In clinical practice, intima-media thickness, mainly carotid (CIMT), has been used as a marker of subclinical atherosclero$\operatorname{sis}^{13}$. In fact, increased CIMT has been associated with aging, but also with sleep disorders, such as obstructive sleep apnea, short sleep and long sleep ${ }^{13,14}$. However, the actual burden of sleep disorders over CIMT in young adults remains unclear because its progression is affected by other potential confounders, such as sex, age, and dyslipidemia ${ }^{13}$. Moreover, the effect of other behavioral variables, like physical activity, alcohol consumption and smoking, on the possible relationship between CIMT and insomnia / hypersomnia is not very well explored.

Thus, the aim of this study was to analyze the relationship between sleep disorders (insomnia and hypersomnia), behavioral variables and intima-media thickness in young adults.

\section{Methods}

\section{Subjects}

The present study was part of the longitudinal study titled "Maintenance of physical activity throughout life and vascular stiffness in adults: cross-sectional analysis and cohort of 12 months". The present data are from the baseline measurements, which happened during the second half of 2013, and involved a sample of 100 adults of both genders, aged 30-50 years old. Inclusion criteria were defined as: (i) age between $30-50$ years old; (ii) no previous history of stroke or myocardial infarction; (iii) no amputation or visual problems related to diabetes mellitus; (iv) no physical limitation that could affect physical activity engagement; (v) either presence or absence of sports participate on in both childhood and adolescence; (vi) sign consent form to participate. 
The sample was composed of university employees (faculty, office, and general services staff) and people engaged in sports clubs of the city. The university staff composed $50 \%$ of all participants, were randomly selected and invited to participate in the study. Initially, 122 subjects were accepted to participate in the present study, but after a face-to-face interview and carefully checking the inclusion criteria, the final sample was composed of 100 subjects of both genders (54 men and 46 women). Experimental procedures were approved by the Ethical Research Group of the Universidade Estadual Paulista (UNESP), Presidente Prudente, Brazil (CAAE: 07770112.3.0000.5402).

\section{Dependent variable}

\section{Carotid intima-media thickness measurements}

A Doppler ultrasound device (Toshiba Xario, SSA-660A) was used to assess CIMT. All tests were performed at the hospital during the morning, from 8:00 - 11:00 am, and the analyzes were performed by a medical doctor specialized in diagnostic for imaging. The procedures adopted for the exams followed the recommendations of the Brazilian Society of Cardiology ${ }^{15}$. Prior to the tests, all subjects were resting in a supine position in a quiet and acclimatized room. To measure CIMT, the neck was positioned in hyperextension and slightly inclined at $45^{\circ}$. The measurements were carried out in the posterior wall, farthest from the transducer, manually and with the caliper method. Three measurements were obtained in the stretch of $15 \mathrm{~mm}$ focal free plates, where the pattern is clearly observed. For analysis of the results, we considered mean values in millimeters $(\mathrm{mm})$.

\section{Independent variable}

\section{Quality of sleep}

The quality of sleep was assessed by the Mini-Sleep Questionnaire (MSQ), previously validated for Brazilian Portuguese $^{16}$. The questionnaire consisted of 10 questions with seven possible answers (never $=1$, very rarely $=2$, rarely $=3$, sometimes $=4$, often $=5$, very often $=6$ and always $=7$ ). The sum of the 10 responses generated a numerical score, which was organized into four categories: good sleep (score 10 to 24 points), slightly altered sleep (score between 25 and 27 points), moderately altered sleep (score between 28 and 30 points) and very altered sleep (score above 30 points). Symptoms of insomnia were analyzed by four questions (difficulty in falling asleep, mid-sleep awakenings, early awakening [morning], and use of sleep medication) and hypersomnia by six questions (snoring, feeling tired after awakening, excessive daytime sleepiness, and restless sleep) ${ }^{16}$.

We characterized "disturbed sleep" score $\geq 25$ points. Furthermore, the numerical score was analyzed in three ways: overall (sum of the 10 questions), insomnia (sum of the four questions related to insomnia) and hypersomnia (sum of the six questions related to insomnia).

\section{Potential confounders}

\section{General variables}

Body fat (in percentage) was assessed using a dual-energy $\mathrm{x}$ ray absorptiometry (DXA) scanner (Lunar DPX-NT; General Electric Healthcare, Little Chalfont, Buckinghamshire, UK) with GE Medical System Lunar software (version 4.7). DXA measures were performed during the morning after a light breakfast, and the scanner quality was tested by a trained researcher before each day of measurement, following the manufacturer's recommendations. The participants wore light clothing, without shoes and remained in the supine position on the machine (approximately $15 \mathrm{~min}$ ).

Chronological age, sex, and race were registered. Systolic and diastolic blood pressures (SBP and DBP) were measured indirectly by auscultation using a sphygmomanometer $(\mathrm{Bic} \AA)$ and stethoscope (Classic II SE, Littmann ${ }^{\circledR}$ ) at the laboratory in a controlled temperature room according to standardized protocols ${ }^{15}$. The number of cardiovascular diseases/events (e.g. arterial hypertension, diabetes mellitus, stroke and heart attack) in the family (father, mother, brothers) was registered and used as a proxy of family history of cardiovascular diseases.

\section{Metabolic/Inflammatory variables}

Blood samples were collected and biochemical analyses were performed in a private laboratory, which reaches the quality control adopted by the Brazilian Health Ministry. Blood samples were collected after 12-hour fasting. High sensitive C-reactive protein (hsCRP) was determined using an enzyme-linked immunoturbidimetric assay kit (Millipore, St Charles, MO [intraand inter- assay coefficients of variation were 4.6 and $6.0 \%$, respectively]). Fasting glucose was managed by an enzymatic colorimetric kit and processed in a unit Autohumalyzer A5 ${ }^{17}$.

Blood levels of insulin were estimated by chemiluminescence according to Burtis, Ashwood, Bruns ${ }^{18}$. HOMA-IR was obtained considering fasting blood glucose $(\mathrm{mmol} / \mathrm{L})$ and fasting blood insulin (IU/mL), using the following formula: (glucose* insulin) $\div 22.5^{19}$. Glycated hemoglobin $(\mathrm{HbA1C})$ was obtained from blood samples and stored in vacuum sealed tubes containing ethylenediaminetetraacetic acid (EDTA) as anticoagulant lyophilized. The determination of the glycated hemoglobin was performed in a primary tube by high-performance liquid chromatography (HPLC) equipment in D10 - Hemoglobin A1C Testing System (Bio-Rad ${ }^{\circledR}$, France $)^{20,21}$.

\section{Behavioral variables}

Current physical activity was assessed using pedometers (DigiWalker Yamax, SW200), which were fixed laterally at the hip. 
Participants were instructed to remove the device while sleeping, showering and performing aquatic activities. The pedometer was used for seven consecutive days. At the end of each day, the participants recorded the number of steps taken throughout the day. Each morning, the "reset" button was pushed to zero out the device and start collecting new data. The average number of steps for the week was assigned as the level of habitual physical activity ${ }^{22}$.

Smoking was analyzed according to the number of cigarettes smoked per day (cigarettes/day). Alcohol consumption was assessed by self-report of the frequency of alcohol consumption in a common week (never $=1$, sometimes $=2$, often $=3$, very often $=4$ and always $=5$ ). Skipping meals was analyzed through the frequency of eating meals like breakfast, dinner, and lunch.

\section{Statistical analysis}

Mean and standard deviation (SD) were used as descriptive statistics. Independent sample t-tests were used to compare participants according to sleep quality (good and disturbed). Measurements of effect size were provided by the Cohen's $d$ test (Effect size: Small $\geq 0.20$, Medium $\geq 0.50$, Large $\geq 0.80$ and Very Large $\geq 1.30$ ). Pearson correlation was used to analyze the relationship between CIMT, MSQ scores, and all independent variables. Finally, the linear regression model was used (expressed as beta values $[\beta]$ and $95 \%$ confidence interval $[\beta 95 \% \mathrm{CI}])$, and the variables significantly related to CIMT in the Pearson correlation were inserted simultaneously in the multivariate model. In this final multivariate model, CMIT and insomnia were both logarithm transformed. All analyses were performed by the statistical software BioEstat (release 5.0 [BioEstat, Tefé, Amazonas]) and statistical significance was set at $5 \%$.

\section{Results}

In the present study, the occurrence of sleep-related disorders was $47 \%(95 \% \mathrm{CI}=37.2 \%$ - 56.7\%) (Table 1). Participants

CIMT was positively related to smoking habit, alcohol consumption, age and SBP (correlations ranging from $r=0.19$ to $r=0.34$ [Table 2]). Body fat and HOMA-IR were related to insomnia. Higher physical activity level was significantly related to better quality of sleep $(r=-0.29$; $\mathrm{p}$-value $=0.001)$ and lower symptoms reporting sleep-related disorders had significantly higher values of HOMA-IR (Medium effect size), body fat (Medium effect size) and CIMT (Small effect size) than those without sleep disorders. HbA1c was marginally significant ( $p$-value $=0.090)$, but presented very large effect size. Moreover, the current physical activity level was $25 \%$ significantly higher in adults without sleep-related disorders than those with sleep-related disorders (Medium effect size).

Table 1. General characteristics of the sample stratified by sleep quality among young adults.

\begin{tabular}{cccc}
\hline $\begin{array}{c}\text { Independent } \\
\text { Variables }\end{array}$ & $\begin{array}{c}\text { Good Sleep } \\
(\mathbf{n}=\mathbf{5 3})\end{array}$ & $\begin{array}{c}\text { Disturbed Sleep } \\
(\mathbf{n}=\mathbf{4 7})\end{array}$ & $\begin{array}{c}\text { Cohen's d } \\
\text { (effect size) }\end{array}$ \\
\cline { 2 - 3 } & Mean (SD) & Mean (SD) & \\
\hline Sex (M/F) & $30 / 23$ & $24 / 23$ & --- \\
Age $_{(\text {years })}$ & $38.7(3.8)$ & $39.7(5.8)$ & $-0.206^{\text {Small }}$ \\
Glucose $_{(\mathrm{mg} / \mathrm{dL})}$ & $90.9(9.1)$ & $98.2(32.6)$ & $-0.313^{\text {Small }}$ \\
Insulin & $5.6(3.2)$ & $7.6(4.6)^{*}$ & $-0.510^{\text {Medium }}$ \\
hSCRP $_{(\mathrm{mg} / \mathrm{dL})}$ & $3.1(3.9)$ & $3.1(3.9)$ & $-0.225^{\text {Small }}$ \\
$\mathrm{HOMA}^{\mathrm{IR}}$ & $1.29(0.84)$ & $1.92(1.51)^{*}$ & $-0.524^{\text {Medium }}$ \\
$\mathrm{Steps}_{\mathrm{day}}$ & $9731.4(3746.3)$ & $7743.9(3181.1)^{*}$ & $0.569^{\text {Medium }}$ \\
$\mathrm{BF}_{(\%)}$ & $29.4(11.3)$ & $34.8(9.9)^{*}$ & $-0.506^{\text {Medium }}$ \\
$\mathrm{SBP}_{(\mathrm{mmHg})}$ & $110.7(12.9)$ & $111.6(10.6)$ & $-0.076^{\text {Trivial }}$ \\
$\mathrm{DBP}_{(\mathrm{mmHg})}$ & $77.7(7.5)$ & $78.9(8.1)$ & $-0.154^{\text {Trivial }}$ \\
$\mathrm{CMIT}_{(\mathrm{mm})}$ & $0.63(0.15)$ & $0.70(0.14)^{*}$ & $-0.481^{\text {Small }}$ \\
\hline
\end{tabular}

*= Student $\mathrm{t}$ test with $\mathrm{p}$-value $<0.05 ; \mathrm{CIMT}=$ carotid intima media thickness; HOMA-IR = homeostasis model assessment - insulin resistance; $\mathrm{BF}=$ body fatness; hsCRP $=$ high sensitivity $\mathrm{C}$-reactive protein; $\mathrm{SBP}=$ systolic blood pressure; $\mathrm{DBP}=$ diastolic blood pressure.

of hypersomnia (snoring, feeling tired after awakening, excessive daytime sleepiness, and restless sleep $[\mathrm{r}=-0.30 ; \mathrm{p}$-value $=0.002]$ ), while higher age was related to increased symptoms of insomnia (difficulty in falling asleep, mid-sleep awakenings, early awakening, and use of sleep medication $[\mathrm{r}=0.19$; $\mathrm{p}$-value $=0.047]$ ).

Table 2. Relationship between intima-media thickness, sleep and metabolic, inflammatory, behavioral variables among young adults.

\begin{tabular}{|c|c|c|c|c|}
\hline \multirow{2}{*}{ Independent variables } & CIMT & MSQ $_{\text {overall }}$ & MSQ $_{\text {Insomnia }}$ & MSQ $_{\text {hypersomnia }}$ \\
\hline & $r(\mathbf{9 5 \%} \% \mathrm{CI})$ & $r(\mathbf{9 5 \%} \mathrm{CI})$ & $r(\mathbf{9 5 \%} \mathrm{CI})$ & $r(\mathbf{9 5 \%} \% \mathrm{CI})$ \\
\hline \multicolumn{5}{|l|}{ Behavioral variables } \\
\hline Physical activity (mean steps/day) & $-0.09(-0.28$ to 0.10$)$ & $-0.29(-0.46 \text { to }-0.09)^{*}$ & $-0.19(-0.37$ to -0.01$)$ & $-0.31(-0.46 \text { to }-0.11)^{*}$ \\
\hline Smoking (cigarettes/day) & $0.34(0.15 \text { to } 0.50)^{*}$ & $0.13(-0.06$ to 0.31$)$ & $0.08(-0.11$ to 0.27$)$ & $0.14(-0.05$ to 0.32$)$ \\
\hline Alcohol (days/week) & $0.20(0.01 \text { to } 0.38)^{*}$ & $0.07(-0.12$ to 0.26$)$ & $0.17(-0.02$ to 0.35$)$ & $0.01(-0.18$ to 0.20$)$ \\
\hline
\end{tabular}


Control variables

\begin{tabular}{|c|c|c|c|c|c|}
\hline HOMA-IR & $0.10(-0.09$ to 0.29$)$ & $0.20(0.01 \text { to } 0.38)^{*}$ & $0.20(0.01 \text { to } 0.38)^{*}$ & & $0.17(-0.02$ to 0.35$)$ \\
\hline $\mathrm{hsCRP}(\mathrm{mg} / \mathrm{dL})$ & $-0.02(-0.22$ to 0.16$)$ & $0.15(-0.04$ to 0.33$)$ & $-0.01(-0.20$ to 0.18$)$ & & $0.20(0.01 \text { to } 0.38)^{*}$ \\
\hline $\mathrm{BF}(\%)$ & $-0.01(-0.20$ to 0.18$)$ & $0.31(0.12 \text { to } 0.47)^{*}$ & $0.21(0.02 \text { to } 0.38)^{*}$ & & $0.31(0.12 \text { to } 0.47)^{*}$ \\
\hline Sex & $-0.16(-0.34$ to 0.03$)$ & $0.03(-0.16$ to 0.22$)$ & $0.01(-0.18$ to 0.20$)$ & & $0.04(-0.15$ to 0.23$)$ \\
\hline Age (yes) & $0.26(0.06 \text { to } 0.43)^{*}$ & $0.04(-0.15$ to 0.23$)$ & $0.19(0.01 \text { to } 0.37)^{*}$ & & $-0.04(-0.23$ to 0.15$)$ \\
\hline SBP (mmHg) & $0.19(0.01 \text { to } 0.38)^{*}$ & $0.04(-0.15$ to 0.23$)$ & $0.05(-0.14$ to 0.24$)$ & & $0.02(-0.17$ to 0.21$)$ \\
\hline DBP (mmHg) & $0.18(-0.01$ to 0.36$)$ & $0.10(-0.09$ to 0.29$)$ & $0.06(-0.13$ to 0.25$)$ & & $0.09(-0.10$ to 0.28$)$ \\
\hline \multicolumn{6}{|l|}{ Sleep variables } \\
\hline $\mathrm{MSQ}_{\text {overall }}$ & $0.20(0.01 \text { to } 0.38)^{*}$ & --- & --- & --- & \\
\hline $\mathrm{MSQ}_{\text {Insomnia }}$ & $0.30(0.11 \text { to } 0.46)^{*}$ & --- & --- & --- & \\
\hline MSQ $_{\text {hypersomnia }}$ & $0.10(-0.09$ to 0.29$)$ & --- & --- & --- & \\
\hline
\end{tabular}

Notes: 95\%CI=95\% confidence interval; CIMT= carotid intima media thickness; MSQ= Mini-Sleep Questionnaire; HOMA-IR= homeostasis model assessment insulin resistance; $\mathrm{BF}=$ body fatness; $\mathrm{SBP}=$ systolic blood pressure; $\mathrm{DBP}=$ diastolic blood pressure; hsCRP= high sensitive $\mathrm{C}$-reactive protein; $*=\mathrm{p}$-value $<0.05$.

CIMT was positively related with bad sleep quality $(\mathrm{r}=$ 0.20 [0.01 to 0.38$]$ ) and increased symptoms of insomnia $(\mathrm{r}=0.30$ [0.11 to 0.46$])$. On the other hand, in the multivariate model (after adjustments), only the relationship between CIMT and insomnia remained statistically significant (Table 3). Similarly, smoking and cluster of behaviors still remained related to CIMT.

Table 3. Relationship between sleep quality and intima media thickness among young adults.

\begin{tabular}{|c|c|c|c|}
\hline \multirow{3}{*}{ Independent Variables } & \multicolumn{3}{|c|}{ Linear Regression Models } \\
\hline & \multicolumn{3}{|c|}{$\begin{array}{l}\text { Outcome: carotid Intima Media } \\
\text { Thickness }\end{array}$} \\
\hline & $\boldsymbol{\beta}$ & $\left(\boldsymbol{\beta}_{95 \% \mathrm{CI}}\right)$ & $p$-value \\
\hline \multicolumn{4}{|l|}{ Model - 1} \\
\hline $\mathrm{MSQ}_{\text {overall }}$ & 0.158 & $(-0.050$ to 0.365$)$ & 0.135 \\
\hline $\mathrm{MSQ}_{\text {Insomnia }}$ & 0.191 & $(0.026$ to 0.356$)$ & 0.023 \\
\hline \multicolumn{4}{|l|}{ Model - 2} \\
\hline $\begin{array}{l}\text { Smoking (cigarettes/ } \\
\text { day) }\end{array}$ & 0.071 & (0.010 to 0.133$)$ & 0.024 \\
\hline Alcohol (days/week) & 0.021 & $(-0.004$ to 0.046$)$ & 0.099 \\
\hline \multicolumn{4}{|l|}{ Model - 3} \\
\hline $\begin{array}{l}\text { Cluster }_{\text {smoke, alcohol and physical }} \\
\text { inactivity }\end{array}$ & 0.030 & (0.006 to 0.054$)$ & 0.014 \\
\hline
\end{tabular}

Notes: Model-1= MSQ overall and MSQ insomnia entered separately and then the model was adjusted by age, systolic blood pressure, smoking and alcohol consumption; Model-2= Smoking and Alcohol entered simultaneously and then adjusted by age and systolic blood pressure; Model-3= adjusted by age, systolic blood pressure, HOMA-IR, C-reactive protein and body fatness percentage; $95 \% \mathrm{CI}=95 \%$ confidence interval; MSQ= Mini-Sleep Questionnaire.

\section{Discussion}

The main results of the present study show that insomnia in young adults is significantly related to higher carotid intimamedia thickness. There are compelling evidences supporting that over the last decade, sleep time has decreased in both sexes independently of age ${ }^{23}$. Moreover, more than $30 \%$ of the American population reports sleep disorders ${ }^{23}$. The disorders related to sleep do not allow adequate biological rest and have consequences in the daily energy demands. Insomnia, hypersomnia and somnambulism are some of the examples that can cause this type of disorders ${ }^{6}$. This alarming background is also observed in developing nations, such as Brazil. In Sao Paulo, the most industrialized Brazilian city, the number of adults reporting sleep-related disorder increased significantly between 1987 and $2007^{24}$. In addition, Bittencourt, Santos-Silva, Taddei, Andersen, de Mello, Tufik ${ }^{25}$ described that $35 \%$ of the Brazilian adults have insomnia. Findings of the present study are consistent with the previous research claiming effective strategies to promote healthy sleep habits in developing countries.

Cumulative evidence suggests an important link between sleep disorders and cardiovascular diseases ${ }^{26-28}$. Patients with sleep disorders have high cardiovascular risk profile, given the higher prevalence of conventional risk factors including obesity, diabetes mellitus, and hypertension ${ }^{29,30}$. Fox and colleagues found that patients with sleep disorders but free of cardiovascular diseases and conventional risk factors, such as body mass index, age and sex, presented a significant correlation when compared to controls. These findings prove that confounders, such as age, sleep disturbances, conventional risk factors (unhealthy behaviors [e.g. alcohol consumption and smoking] and higher food intake) and cardiovascular diseases, are notably linked, being able to favor the development of some pathological condition that affects health of the people.

Regarding physical activity, there was no correlation with sleep disturbances. However, this variable is considered 
a protective factor for several pathological conditions, as evidenced by Søren Spörndly-Nees and colleagues ${ }^{31}$. The authors found that women who performed physical activity at moderate to high intensity during 10 years showed a protective factor against insomnia, independently of psychological stress, age, body mass index, smoking, alcohol consumption or educational level.

Results of the present study revealed that SBP and age were positively related to CMIT, while age and insomnia were also positively related to each other. Insomnia is defined as sleep difficulties and aging is commonly associated with insomnia diagnosis ${ }^{32}$. At the same time, insomnia is linked to cardiovascular disorders and depressive symptoms ${ }^{32,33}$, mainly in elderlies ${ }^{33}$. The autonomic nervous system stimulates blood pressure according to the metabolic demand of the movement aiming vasoconstriction and acceleration of cardio functions of the sympathetic nervous system, producing a reciprocal inhibition of the parasympathetic vagal signals on the parasympathetic vascular effects. Thus, when both effects are combined they generate an increase in blood pressure ${ }^{34}$. Studies have demonstrated how sympathetic system activities, such as catecholamines and the period of cardiac pre-ejection, decrease with the sleep progression, whereas in the parasympathetic measurements variables, such as the RR interval, change as early as two hours before sleep time ${ }^{35}$.

The biological processes during aging affect the circadian rhythms and, hence, body temperature and secretion of melato$\operatorname{nin}^{32}$, which affect sleep quality. Moreover, older people present increased sympathetic activity and decreased parasympathetic activity $^{36,37}$ accompanied by weight gain ${ }^{38}$, which are relevant risk factors for high blood pressure and increased CIMT.

In agreement with other studies ${ }^{27}$, our sample had age ranging from 30-50 years old, and insomnia and CIMT were significantly related. This finding identifies that insomnia seems to affect cardiovascular health not only in elderly, but also among young adults suggesting that these symptoms occur from early adulthood to older ages, and thus, preventive actions targeting improvement of sleep quality in young populations seem to be relevant to prevent diseases among elderlies in the future.

Among young adults, smoking and alcohol consumption were behaviors related to higher CIMT. Cigarette smoking has been linked to the development of atherosclerosis due to its harmful action in different pathways related to the deposition of lipids in the arterial wall ${ }^{39,40}$ and increases the production of reactive oxygen species, which is closely linked to insulin resistance, significant decreases bioavailability of nitric oxide, and increases lipid oxidation and recruitment of adhesion molecules ${ }^{40}$. Moreover, this habit seems to intensify the natural effect of aging in the vascular wall ${ }^{40}$. The physiological mechanism linking alcohol consumption and atherosclerosis is similar to smoking and depends on the amount of alcohol ingested ${ }^{41}$. While low alcohol ingestion is related to protective cardiovascular effect mainly red wine ingestion, high alcohol ingestion is related to insulin resistance and subsequent oxidative stress ${ }^{41}$.

Separately, cigarette smoking and alcohol consumption were not related to insomnia and in the final multivariate model both variables did not demonstrate statistical significance, but when grouped together, there was significant relationship with insomnia $(\mathrm{r}=0.199[0.003$ to 0.381$])$ and the relationship with CIMT increased slightly $(\mathrm{r}=0.242$ [0.048 to 0.419$])$. Therefore, our findings seem to identify that clustering of unhealthy behavioral constitutes relevant risk factor related to insomnia and atherosclerosis in young adults, which should be avoided in this population due to its characteristics of maintenance throughout life.

The present study revealed a significant relationship between insomnia and CIMT independently of age, SBP, cigarette smoking and alcohol consumption, but also identified that insomnia was related to body fat and insulin resistance. There is limited data about insomnia, but it is well documented that other sleep disturbances and shorter duration of sleep are factors associated with higher weight gain and dyslipidemia ${ }^{42-45}$.

Magee, Huang, Iverson, Caputi ${ }^{46}$ identified three possible pathways by which sleep and obesity are linked: i) alterations in neuroendocrine and metabolic functioning (sleep deprivation affects cortisol levels, reduces leptin and increases ghrelin in bloodstream), ii) alteration in glucose regulation (sleep deprivation leads to insulin resistance and, hence, dyslipidemia) and iii) modifications in waking behaviors (during waking time, there is sedentary behavior [e.g. watching TV and computer usage] and higher food intake). However, it is unclear the causality between obesity and development of sleep insomnia and, therefore, further research is needed, particularly with a prospective design.

Diabetes mellitus (DM) is a progressive and complex disease that is tightly associated with heterogeneous metabolic disorders, particularly in glucose and lipid metabolism ${ }^{47}$. In patients with $\mathrm{DM}$, the production of insulin is limited and the cells do not respond adequately to the stimuli, exhibiting insulin resistance, which causes a dangerous high concentration of glucose in the blood and can trigger metabolic deficits that are harmful to health ${ }^{48}$. Regarding our findings from the HOMA-IR and HbA1, it has been evidenced that the results can be directly related to the genotype and daily behavioral habits. These two components increase the chances of developing a metabolic disorder, such as $\mathrm{DM}^{49}$. Eun-Jung Rhee and colleagues analyzed the association between baseline lipoprotein and DM risk after four years of follow-up, and found that low baseline lipoprotein levels led to a greater predisposition to develop $\mathrm{DM}^{49}$. Despite the results of current studies, it is still sought to clarify how sleep disorders can directly or indirectly influence the development of pathological conditions.

Limitations should be recognized. Despite being based on the hypothesis with consistent biologic plausibility, the main limitation of the study is its cross-sectional design, disabling cause-effect relationships. Moreover, although pedometer constitutes an interesting tool to measure physical activity, the device does not provide data about intensity, which could affect the relationship between physical activity and sleep quality ${ }^{50}$. On the other hand, neck circumference was not measured, which may have significant relevance concerning sleep disturbances. Thus, we emphasize the need for future research with clinical factors and signs that can give a more precise response to the correlation of sleep disturbances with potential confounders.

In conclusion, the present study revealed that insomnia in young adults is significantly related to higher CIMT. In addition, the presence of certain behavioral habits, such as poor sleep or 
diet, may cause increased body fat, resulting in an inadequate production and receptivity of insulin.

\section{References}

1. Carter PJ, Taylor BJ, Williams SM, Taylor RW. Longitudinal analysis of sleep in relation to BMI and body fat in children: the FLAME study. Bmj. 2011;342:d2712.

2. Foster RG, Kreitzman L. The rhythms of life: what your body clock means to you! Exp Physiol. 2014;99(4):599-606.

3. Calhoun SL, Fernandez-Mendoza J, Vgontzas AN, Liao D, Bixler EO. Prevalence of insomnia symptoms in a general population sample of young children and preadolescents: gender effects. Sleep Med. 2014;15(1):91-5.

4. Rey-López J, De Carvalho H, de Moraes A, Ruiz J, Sjöström $\mathrm{M}, \mathrm{Marcos} \mathrm{A}$, et al. Sleep time and cardiovascular risk factors in adolescents: The HELENA (Healthy Lifestyle in Europe by Nutrition in Adolescence) study. Sleep Med. 2014;15(1):104-10.

5. Zimberg IZ, Dâmaso A, Del Re M, Carneiro AM, Sá Souza H, Lira FS, et al. Short sleep duration and obesity: mechanisms and future perspectives. Cell Biochem Funct. 2012;30(6):524-9.

6. Ohayon MM. Epidemiology of insomnia: what we know and what we still need to learn. Sleep Med Rev. 2002;6(2):97-111.

7. Kobayashi D, Takahashi O, Deshpande GA, Shimbo T, Fukui T. Relation between metabolic syndrome and sleep duration in Japan: a large scale cross-sectional study. Intern Med. 2011;50(2):103-7.

8. Pandey A, Williams N, Donat M, Ceide M, Brimah P, Ogedegbe $\mathrm{G}$, et al. Linking sleep to hypertension: greater risk for blacks. Int J Hypertens. 2013;2013.

9. Vgontzas AN, Liao D, Pejovic S, Calhoun S, Karataraki M, Bixler EO. Insomnia with objective short sleep duration is associated with type 2 diabetes. Diabetes care. 2009;32(11):1980-5.

10. Mullington JM, Haack M, Toth M, Serrador JM, Meier-Ewert HK. Cardiovascular, inflammatory, and metabolic consequences of sleep deprivation. Prog Cardiovasc Dis. 2009;51(4):294-302.

11. Singareddy R, Vgontzas AN, Fernandez-Mendoza J, Liao D, Calhoun S, Shaffer ML, et al. Risk factors for incident chronic insomnia: a general population prospective study. Sleep med. 2012;13(4):346-53.

12. Santana AA, Pimentel GD, Romualdo M, Oyama LM, Santos RVT, Pinho RA, et al. Sleep duration in elderly obese patients correlated negatively with intake fatty. Lipids Health Dis. 2012;11(1):99.

13. Nadeem R, Harvey M, Singh M, Khan AA, Albustani M, Baessler A, et al. Patients with obstructive sleep apnea display increased carotid intima media: a meta-analysis. Int J Vasc Med. 2013;2013.

14. Sands MR, Lauderdale DS, Liu K, Knutson KL, Matthews $\mathrm{KA}$, Eaton $\mathrm{CB}$, et al. Short sleep duration is associated with carotid intima-media thickness among men in the Coronary Artery Risk Development in Young Adults (CARDIA) Study. Stroke. 2012;43(11):2858-64.

15. Nogueira ACS, Schettino CD, Barros MVL, Alcantara MLd, Studart PCdC, Araújo PPd, et al. Normatização dos equipamentos e das técnicas para a realização de exames de ultra-sonografia vascular. Arq Bras Cardiol. 2004;82:1-14.

16. Falavigna A, de Souza Bezerra ML, Teles AR, Kleber FD, Velho MC, Da Silva RC, et al. Consistency and reliability of the Brazilian Portuguese version of the Mini-Sleep Questionnaire in undergraduate students. Sleep Breath. 2011;15(3):351-5.
17. Human R, Jones G. Evaluation of swab transport systems against a published standard. J Clin Pathol. 2004;57(7):762-3.

18. Burtis CA, Ashwood ER, Bruns DE. Tietz, Textbook of Clinical Chemistry and Molecular Diagnostics. FIFTH EDITION ed. ELSEVIER, 2012.

19. Yang T. Insulin sensitivity and beta-cell function are associated with arterial stiffness in individuals without hypertension. J Diabetes Res. 2013;2013.

20. Little RR, England JD, Wiedmeyer H-M, Goldstein DE. Effects of whole blood storage on results for glycosylated hemoglobin as measured by ion-exchange chromatography, affinity chromatography, and colorimetry. Clin Chem. 1983;29(6):1113-5.

21. Panzer S, Kronik G, Lechner K, Bettelheim P, Neumann E, Dudczak R. Glycosylated hemoglobins (GHb): an index of red cell survival. Blood. 1982;59(6):1348-50.

22. Tudor-Locke C, Craig CL, Aoyagi Y, Bell RC, Croteau KA, De Bourdeaudhuij I, et al. How many steps/day are enough? For older adults and special populations. Int J Behav Nutr Phys Act. 2011;8(1):80.

23. Luyster FS, Strollo Jr PJ, Zee PC, Walsh JK. Sleep: a health imperative. Sleep. 2012;35(6):727-34.

24. Santos-Silva R, Bittencourt LRA, Pires MLN, de Mello MT, Taddei JA, Benedito-Silva AA, et al. Increasing trends of sleep complaints in the city of Sao Paulo, Brazil. Sleep Med. 2010;11(6):520-4.

25. Bittencourt L, Santos-Silva R, Taddei JA, Andersen ML, de Mello MT, Tufik S. Sleep complaints in the adult Brazilian population: a national survey based on screening questions. J Clin Sleep Med. 2009;5(5):459-63.

26. Badran M, Ayas N, Laher I. Cardiovascular complications of sleep apnea: role of oxidative stress. Oxid Med Cell Longev. 2014;2014.

27. Bradley TD, Floras JS. Obstructive sleep apnoea and its cardiovascular consequences. Lancet. 2009;373(9657):82-93.

28. Kato M, Roberts-Thomson P, Phillips BG, Haynes WG, Winnicki $\mathrm{M}$, Accurso V, et al. Impairment of endothelium-dependent vasodilation of resistance vessels in patients with obstructive sleep apnea. Circulation. 2000;102(21):2607-10.

29. Marin JM, Agusti A, Villar I, Forner M, Nieto D, Carrizo SJ, et al. Association between treated and untreated obstructive sleep apnea and risk of hypertension. JAMA. 2012;307(20):2169-76.

30. Nieto FJ, Young TB, Lind BK, Shahar E, Samet JM, Redline $\mathrm{S}$, et al. Association of sleep-disordered breathing, sleep apnea, and hypertension in a large community-based study. JAMA. 2000;283(14):1829-36.

31. Spörndly-Nees S, Åsenlöf P, Lindberg E. High or increasing levels of physical activity protect women from future insomnia. Sleep Med. 2017;32:22-7.

32. Costa IC, Carvalho HN, Fernandes L. Aging, circadian rhythms and depressive disorders. Am J Neurodegener Dis. 2013;2(4):228-46.

33. Nagai M, Hoshide S, Nishikawa M, Shimada K, Kario K. Sleep duration and insomnia in the elderly: associations with blood pressure variability and carotid artery remodeling. Am J Hypertens. 2013:hpt070.

34. Lambert E, Sari CI, Dawood T, Nguyen J, McGrane M, Eikelis $\mathrm{N}$, et al. Sympathetic nervous system activity is associated with obesity-induced subclinical organ damage in young adults. Hypertension. 2010;56(3):351-8.

35. Spaak J, Egri ZJ, Kubo T, Yu E, Ando S-I, Kaneko Y, et al. Muscle sympathetic nerve activity during wakefulness in heart 
failure patients with and without sleep apnea. Hypertension. 2005;46(6):1327-32.

36. Gangwisch JE, Heymsfield SB, Boden-Albala B, Buijs RM, Kreier F, Pickering TG, et al. Short sleep duration as a risk factor for hypertension. Hypertension. 2006;47(5):833-9.

37. Wichi RB, De Angelis K, Jones L, Irigoyen MC. A brief review of chronic exercise intervention to prevent autonomic nervous system changes during the aging process. Clinics. 2009;64(3):253-8.

38. Gigante DP, Moura ECd, Sardinha LMV. Prevalence of overweight and obesity and associated factors, Brazil, 2006. Rev Saude Publica. 2009;43:83-9.

39. Ambrose JA, Barua RS. The pathophysiology of cigarette smoking and cardiovascular disease: an update. J Am Coll Cardiol. 2004;43(10):1731-7.

40. Li S, Yun M, Fernandez C, Xu J, Srinivasan SR, Chen W, et al. Cigarette smoking exacerbates the adverse effects of age and metabolic syndrome on subclinical atherosclerosis: the Bogalusa Heart Study. PloS one. 2014;9(5):e96368.

41. Cahill PA, Redmond EM. Alcohol and cardiovascular diseasemodulation of vascular cell function. Nutrients. 2012;4(4):297-318.

42. Beccuti G, Pannain S. Sleep and obesity. Curr Opin clin Nutr Metab Care. 2011;14(4):402.

43. Iguchi A, Yamakage H, Tochiya M, Muranaka K, Sasaki Y, Kono $\mathrm{S}$, et al. Effects of weight reduction therapy on obstructive sleep apnea syndrome and arterial stiffness in patients with obesity and metabolic syndrome. J Atheroscler Thromb. 2013;20(11):807-20.

44. Marshall NS, Glozier N, Grunstein RR. Is sleep duration related to obesity? A critical review of the epidemiological evidence. Sleep Med Rev. 2008;12(4):289-98.

45. Patel SR, Hu FB. Short sleep duration and weight gain: a systematic review. Obesity. 2008;16(3):643-53.

46. Magee CA, Huang X-F, Iverson DC, Caputi P. Examining the pathways linking chronic sleep restriction to obesity. J Obes. 2010;2010.

47. Zhong H, Fang C, Fan Y, Lu Y, Wen B, Ren H, et al. Lipidomic profiling reveals distinct differences in plasma lipid composition in healthy, prediabetic and type 2 diabetic individuals. GigaScience. 2017.
48. Zhao Y, Wang Y, Lou H, Shan L. Alpha-glucosidase inhibitors and risk of cancer in patients with diabetes mellitus: a systematic review and meta-analysis. Oncotarget. 2017.

49. Rhee EJ, Cho JH, Lee DY, Kwon H, Park SE, Park CY, et al. Insulin resistance contributes more to the increased risk for diabetes development in subjects with low lipoprotein(a) level than insulin secretion. PLoS One. 2017;12(5):e0177500.

50. Plasqui G. Smart approaches for assessing free $\square$ living energy expenditure following identification of types of physical activity. Obes Rev. 2017;18(S1):50-5.

\section{Acknowledgements}

Financial Support: The Sao Paulo Research Foundation (FAPESP [Process number: 2012/18001-0]) and Brazilian Ministry of Science and Technology (CNPq [Process number: 474484/2012-2]).

Author contributions: S.M. Vanegas elaborated the article, generated the results and wrote the manuscript; B.C. Turi-Lynch, H. C. G. Kemper, F. Santos de Lira, J.S. Condogno, R. A. Fernandes and M.C.Spiguel de Lima contributed to the writing of the manuscript.

\section{Corresponding author}

Santiago Maillane Vanegas.

Department of Physical Therapy, Universidade Estadual Júlio de Mesquita Filho, UNESP. Rua Roberto Símonsen 300, Centro Educacional. 19060 - 900, Presidente Prudente, SP (Brazil).

Email: Santiagovanegas16@gmail.com

Manuscript received on March 20, 2017

Manuscript accepted on June 30, 2017

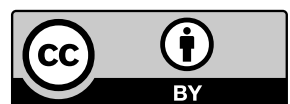

Motriz. The Journal of Physical Education. UNESP. Rio Claro, SP, Brazil - eISSN: 1980-6574 - under a license Creative Commons - Version 3.0 